\title{
FUNDAMENTOS HISTÓRICOS DA SEPARAÇÃO ENTRE TRABALHO DE HOMEM E TRABALHO DE MULHER: algumas notas ${ }^{1}$
}

\author{
Ana Elizabeth Santos Alves ${ }^{2}$ \\ UESB
}

\section{RESUMO:}

Examinamos neste texto explicações a respeito dos fundamentos que legitimam a desigualdade entre os sexos no mundo do trabalho, mediante análise histórica que ilustra as relações sociais entre os sexos. Para tanto, realizamos uma revisão bibliográfica de autores que tratam da gênese da divisão sexual do trabalho a partir da formação da família e das relações sociais de produção na antiguidade, no mundo medieval e capitalista, objetivando elucidar, principalmente, como foram construídas as bases de separação entre trabalho de homens e trabalho de mulheres, consolidada no movimento de separação do lugar do trabalho produtivo do lar para a fábrica, decorrente do processo de industrialização e nesta direção observar quais as funções são designadas para elas.

Palavras-chave: trabalho; divisão sexual do trabalho; processo de industrialização.

\section{BACKGROUND HISTORY OF THE SEPARATION BETWEEN MEN AND WOMEN IN THE WORKPLACE: some notes}

\begin{abstract}
:
We examine his text explanations about the foundations that legitimize gender inequality in the workplace, through historical analysis that illustrates the social relations between the sexes. Therefore, we performed a literature review of authors dealing with the genesis of the sexual division of labor based on family formation and social relations of production in antiquity, in medieval and capitalist world, aiming to elucidate, mainly as bases were constructed separation between working men and women work, consolidated in the movement to separate the place of productive work for the factory, due to the industrial process in this direction and see which functions are assigned to them. .
\end{abstract}

Keywords: work; sexual division of labor; industrial process

\section{APRESENTAÇÃO}

A base da divisão social do trabalho é o resultado da definição das ocupações sociais estabelecidas para o homem e para a mulher na sociedade. Na organização da família e nas posições entre os sexos ao longo da história, podemos observar as condições sociais do trabalho, as relações de poder, as transformações econômicas e políticas, ao mesmo tempo compreender as razões da separação entre trabalhos de homens e trabalhos de mulheres.

O propósito deste artigo é descrever as explicações a respeito dos fundamentos históricos que legitimam a desigualdade entre os sexos, "desnaturalizando" o que é considerado "natural" quando é visível, atualmente, o fato de as mulheres ganharem menos do que os homens, ocuparem as atividades mais precários, uma vez que elas são concebidas como força de trabalho secundária e, assim, dentro dessa lógica hierárquica, há uma maior valoração social do trabalho do homem em detrimento do trabalho da mulher. Para tanto, realizamos uma revisão bibliográfica de autores que tratam da gênese da 
divisão sexual do trabalho a partir da formação da família e das relações sociais de produção na antiguidade, no mundo medieval e capitalista, objetivando elucidar, principalmente, como foram construídas as bases de separação entre trabalho de homens e trabalho de mulheres, consolidada no movimento de separação do lugar do trabalho produtivo do lar para a fábrica, decorrente do processo de industrialização e nesta direção observar quais as funções são designadas para elas.

A família passou a ser reconhecida como uma instituição social a partir da segunda metade do século XIX. O estudo sobre a família com base em critérios científicos teve início no ano de 1861, com o Direito Materno, elaborado por Bachofen, citado por Engels (2002), no qual são formuladas algumas teses sobre as relações entre os sexos.

No mundo antigo, homens e mulheres viviam em comunidades coletivas, onde as relações excluíam a possibilidade de estabelecer, com certeza, a paternidade dos filhos; assim, a filiação apenas podia ser contada segundo a linha feminina, por isso regida pelo direito materno. Nesse modo de vida, as mulheres, como mães, como únicos progenitores, gozavam de grande apreço e respeito. Os relatos de viajantes e missionários acerca da divisão sexual do trabalho, considerando povos ainda em "estado selvagem" e famílias organizadas em uma "economia doméstica comunista", mostram a posição da mulher na sociedade como uma pessoa livre e muito respeitada, em muitas comunidades. (ENGELS, 2002, p. 50-52). Mais tarde, passou a existir outro modelo de família, caracterizado pela relação monogâmica, em que a mulher pertencia a um só homem ${ }^{3}$, no momento em que foram extintas as uniões em grupos e os homens passaram a se ligar a uma só mulher, preocupados em proteger suas propriedades e garantir que a transmissão se manifestasse por meio da herança.

As transformações que ocorreram no centro da organização das famílias, originando a formação da família monogâmica, baseada no predomínio da figura masculina no espaço doméstico, mudaram a posição da mulher e revelaram uma divisão do trabalho segundo uma relação hierárquica de dominação entre o homem e a mulher. A repartição desigual da propriedade tem sua origem na divisão sexual do trabalho na família, cuja distribuição do trabalho e dos produtos é feita de maneira desproporcional, tanto quantitativa quanto qualitativamente entre homens e mulheres. O embrião da apropriação da riqueza é a família.

As descrições feitas por Engels (2002, p. 70-71) das relações familiares na Grécia antiga ilustram o fato:

(...) o primeiro antagonismo de classes que apareceu na história coincide com o desenvolvimento do antagonismo entre o homem e a mulher na monogamia; e a primeira opressão de classes, com a opressão do sexo feminino pelo masculino. A monogamia foi um grande progresso histórico, mas, ao mesmo tempo, iniciou, juntamente com a escravidão e as riquezas privadas, aquele período, que dura até nossos dias, no qual cada progresso é simultaneamente um retrocesso relativo, e o bem-estar e o desenvolvimento de uns se verificam às custas da dor e da repressão de outros. É a forma celular da sociedade civilizada, na qual já podemos estudar a natureza das contradições e dos antagonismos que atingem seu pleno desenvolvimento nessa sociedade.

No mundo antigo, romano e grego, a sociedade era indiferente ao valor do trabalho, cujas relações desenvolviam-se entre escravos, servos e as classes aristocráticas, que 
detinham o poder da terra na produção material no campo. Os papéis relativos a cada sexo eram compreendidos no conjunto das relações sociais. O trabalho era concebido como "estigma fatal ou castigo", pois os homens por natureza eram tidos como desiguais. O trabalho não era considerado digno para se constituir um modo de vida autenticamente humano, mas, sim, um instrumento de tortura - tripalium - (deste termo latino originou-se a palavra trabalho). Portanto, o trabalhador, o escravo, o servo, que pertenciam à terra, cuidavam dos assuntos do trabalho, e os cidadãos dedicavam-se aos assuntos da Polis. Nessa época, as mulheres e os escravos não eram considerados cidadãos. A vida econômica e social das mulheres era descrita pelos historiadores por causa do casamento, da procriação e da vida religiosa. As mulheres escravas serviam para reprodução de escravos ou para prazer dos amos. (PANTEL, 1990).

No mundo grego, o local onde eram tratados os "assuntos dos homens" e dos deuses e a esfera política (a esfera da liberdade) era reservado aos homens, marcando o início da oposição entre os sexos. A distinção implicava que a reprodução biológica e o trabalho dirigido para a sobrevivência, inclusive as atividades desenvolvidas pelo chefe da família, ficassem no espaço privado. Este era o espaço das mulheres e dos escravos. Além dele, para as mulheres, era reservada a participação na vida religiosa da cidade e nos rituais do nascimento e da morte. Elas gozavam de uma "cidadania cultural" e uma relativa autonomia na vida doméstica. Os espaços masculinos e femininos na esfera familiar não eram espaços de liberdade, mas de força, de violência e de desigualdade dominada pelo chefe da família.

O império romano criou mulheres heróicas, corajosas: "nada se opunha intelectualmente à teorização da coragem feminina". Para os romanos, a natureza humana era feita de elementos femininos e masculinos "numa proporção variável e controlável". O lado feminino era fraco e, portanto, as mulheres deveriam ser incentivadas por meio da educação a desenvolver caracteres viris. "A mulher viril era aquela que não cedia às efemeridades femininas" (PANTEL, 1990, p.390 - 391). As mulheres da alta sociedade eram também incentivadas a estudar e a refletir filosoficamente. O filósofo estóico Musónio Rufo (idem, p. 392) afirmava que "as mulheres receberam dos deuses a mesma razão que os homens e a mesma disposição natural para a virtude". O trabalho doméstico era normalmente reservado às esposas como forma de "domínio de si própria, e até de coragem", compreendendo que as moças e os rapazes deveriam ser educados para serem justos, corajosos e moderados.

A divisão social do trabalho e a divisão sexual do trabalho já evidenciavam as desigualdades nas relações sociais entre os homens: a exploração do homem pelo próprio homem e a exploração de gênero. Aos homens livres, era reservada a vida pública, a responsabilidade pelas decisões sobre a vida da cidade. As relações de gênero eram definidas na perspectiva masculina. A vida das mulheres era organizada na família e segundo uma estrutura matrimonial que assegurava a sua invisibilidade e o seu lugar no exercício das tarefas domésticas (sobrevivência da espécie). A apropriação privada dos meios de produção, o trabalho escravo e a transferência das heranças pelo homem a seus consanguíneos impuseram uma organização social de linhagem masculina com a garantia de direito à propriedade. $\mathrm{O}$ trabalho agrícola e a indústria doméstica pertenciam às mulheres: elas teciam tapetes e fabricavam vasilhames.

No mundo medieval, no ocidente cristão, comunidades rurais viviam em uma estrutura fechada pela preponderância da linhagem e dos laços de sangue. A divisão social do trabalho era formada pelos integrantes do clero, que cuidavam da fé cristã, pela nobreza e pelos servos. A organização política era baseada nas relações horizontais no seio da comunidade rural de habitantes ancestralmente compostos por famílias unidas segundo as 
exigências militares e econômicas de relações verticais da sujeição senhorial dominante. $\mathrm{O}$ desenvolvimento das forças produtivas modificou o conteúdo do trabalho, dando origem a melhores métodos de tratamento de matérias-primas, especialização de ofícios e aperfeiçoamento de alguns instrumentos de trabalho para determinados ramos da agricultura e do comércio nos centros urbanos. As atividades de trabalho eram desenvolvidas por camponeses e artesãos proprietários de alguns meios de produção. $\mathrm{O}$ trabalho dos camponeses-servos dividia-se em tempo de trabalho necessário e sobretrabalho não pago apropriado gratuitamente pelo senhor feudal proprietário da terra. (CASTEL, 1998).

O significado dado ao trabalho pelo homem medieval é compreendido, como nos explica Le Goff (1993), pelas heranças culturais legadas, as quais oscilam entre o desprezo e a valorização do trabalho (dualidade trabalho - não trabalho). A herança greco-romana trazia uma ambiguidade entre trabalho e técnica aplicada a atividades que exigem esforço físico e atividades de criação, simbolizada pela dúvida se a mão representa um ato de comando ou de trabalho, como também o peso da ligação entre trabalho e escravidão, relacionada à antítese entre trabalho e liberdade. As heranças bárbaras destacam a importância dos artífices, da virtuosidade técnica, por um lado, e, por outro, o desprezo do guerreiro pelas atividades econômicas e pelo trabalho. A herança judeu-cristã traz antíteses simbólicas nos textos, na prática social e cultural que demonstram a dualidade trabalho versus não trabalho com atitudes valorativas em relação às técnicas e aos artífices e a condenação do homem ao castigo e à penitência do trabalho pelo pecado original.

No campo, o trabalho assalariado era sazonal, dividido entre o cultivo de produtos alimentícios e de matéria-prima; a produção têxtil da cidade e a produção de videiras e a criação de gado, as atividades assentavam-se essencialmente no trabalho familiar camponês. As mulheres cuidavam da casa, dos filhos, da criadagem, da criação de gado e da produção leiteira, da alimentação e ainda participavam da produção têxtil e do pequeno comércio em geral, mas sempre circunscritas ao lar, já que tinham de conciliar os deveres familiares com trabalho produtivo. Os homens trabalhavam junto com as mulheres na produção e transformação de têxteis, na produção dos alimentos. Lavrar e semear a terra eram atividades masculinas, colher os grãos e ceifar o feno em algumas regiões até o início do século XX eram considerados trabalho não especializado executado tanto por homens como por mulheres. OPITZ (1990).

Na medida em que os artesãos iam se deslocando para as cidades, passavam a produzir para um mercado urbano, efetuando trocas comerciais entre empresas familiares autônomas e entre artesãos e comerciantes. $\mathrm{O}$ artesanato na cidade deu continuidade à economia doméstica, desenvolvendo-se em oficinas que produziam bens para a família do senhor e excedentes que eram vendidos em feiras para uma clientela externa. Mais tarde, no transcorrer do século XII, as oficinas, os mestres artesãos se libertaram da relação senhorial e passaram a se organizar de forma mais autônoma, dispondo do monopólio da produção, vendendo diretamente o produto de seu trabalho, e não a sua força de trabalho. (DUBY, 1993). Na cidade, com o crescimento da urbanização, formaram-se os burgos, que absorviam artesãos e comerciantes, crescia a produção para troca e consumo, regida pela lógica das redes de economia doméstica de artesões que se especializaram em um tipo de produção e começaram a depender do mercador para ajudar na comercialização. O trabalho nas oficinas era constituído pelo mestre artesão, proprietário das ferramentas, por artesãos, trabalhadores pagos que ainda não possuíam a sua oficina, trabalhadores temporários (jornaleiros, companheiros) e pelos aprendizes.

Nas cidades medievais, evidenciava-se a divisão material e espiritual do trabalho na separação entre a cidade e o campo. As cidades eram a expressão da divisão do trabalho. 
As contradições latentes afloravam com a oposição entre os interesses dos homens, das mulheres e das crianças na família, entre "os interesses coletivos de todos os indivíduos que se relacionam entre si; e, com efeito, este interesse coletivo não existe apenas na representação, como "interesse geral", mas se apresenta, antes de mais nada, na realidade, como a dependência recíproca de indivíduos entre os quais o trabalho está dividido". Marx e Engels (2007). A divisão do trabalho nas propriedades rurais era marcada entre os senhores, proprietários da terra, os lavradores, considerados pelos senhores como participantes plenos da vida da comunidade na aldeia, e os trabalhadores manuais.

O desenvolvimento da economia urbana artesanal e o aumento da população formavam uma ampla rede de povoações aldeãs, possibilitando homens e mulheres contraírem casamento e constituírem novas organizações econômicas familiares e autônomas. A divisão sexual do trabalho no campo e na cidade era assegurada por uma economia familiar organizada pelo casal e os filhos que trabalhavam em comum nas diversas formas de trabalho assalariado oriundas da divisão do trabalho entre a cidade e o campo. Esses espaços eram constituídos por "domínios de competência" relativos a cada sexo, sem levar em conta uma especificidade rigorosa e coerente; o casal trabalhava em comum.

As mulheres ativas na cidade trabalhavam em oficinas artesanais como mão de obra familiar, mas também como assalariadas em oficinas de vestuário, bolsas, carteiras, bordados. Há relatos da participação de mulheres em profissões que atualmente são consideradas como tipicamente femininas, a exemplo da lavagem de roupa, ou em profissões consideradas hoje como tipicamente masculinas, como a metalurgia ou a construção civil "e em trabalhos fisicamente pesados como serventes aplicando argamassa, a telhar e também nos trabalhos de vidraceiro. Eram contratadas e pagas de acordo com a jornada, constituindo uma mão-de-obra mais barata do que os jornaleiros masculinos". (OPITZ, 1990, p. 401-403).

O trabalho faz parte da vida das famílias, pois não se separa o lugar onde as pessoas moram do lugar do ócio e dos atos sociais dessas pessoas. A mulher camponesa era ligada ao marido no seu trabalho como artífice ou pequeno comerciante, eram unidos por interesses únicos. Ou seja, não se separava o espaço das atividades reprodutivas, de consumo, do espaço das funções produtivas. Entretanto, o espaço da unidade familiar não era homogêneo uma vez que apresentava diferenciações nas relações entre os sexos, entre espaço público e espaço privado. Beauvoir (1949) relata que o marido era o responsável pela mulher, que não tinha quase nenhuma relação direta autônoma com o poder público nem com indivíduos estranhos à família.

O tempo e o ritmo de trabalho eram o dia. O sino, a exemplo da Badia em Florença na Itália dos séculos XI e XII, marca o fim e o início do dia. Dia de trabalho urbano, de uma economia definida pela religião, dominada pelos "ritmos agrários sem pressas, sem preocupações de exatidão, sem inquietações de produtividade". (LE GOFF, 1993, p.6162). A moralidade cristã constituía a fundamental influência na formação do homem, do artífice urbano. O exemplo disso são as corporações de ofícios que não aceitavam mulheres como membros das guildas, pois consideravam que elas representavam a tentação e distraíam o homem do trabalho, não obstante, no mesmo espaço, elas cozinhassem e limpassem as casas das oficinas na cidade. Os membros da igreja julgavam as mulheres propensas à licenciosidade sexual, principalmente se nada tivessem para ocupar as mãos; este preconceito pode ser observado na prática do artesanato com o auxílio da agulha, tanto na tecelagem como no bordado, a fim de manter as mãos das mulheres entretidas. (SENNETT, 2009). 
Na idade moderna (séculos XVI a XVIII), a mentalidade cristã feudal foi perdendo espaço a partir do renascimento comercial e urbano; a abolição dos laços servis e o aparecimento da classe burguesa lentamente iniciaram a transformação da sociedade, imprimindo-lhe um caráter não religioso. O pensamento da época passava a ser dominado por uma ideologia individualista e racionalista. A burguesia ascendente precisava assegurar os seus negócios e, para tanto, passou a contestar a hierarquia social vigente, baseada na desigualdade estabelecida pelo privilégio de nascimento, estimulou o florescimento de uma cultura que lhe garantisse uma posição social compatível com o poder econômico que vinha alcançando. A expansão econômica dessa nova classe foi garantida pela produção e circulação de mercadorias, principais práticas econômicas adotadas no decorrer da expansão ultramarina e na intervenção estatal na economia. Essa política econômica mercantilista promoveu a acumulação primitiva de capitais dentro da Europa, permitindo a países, como a Inglaterra e a França, firmarem-se como potências nos finais do século XVII. (FALCON, 2000; HOBSBAWM, 2002).

Nesse período pré-capitalista, apesar de a ordem feudal ainda estar politicamente implícita, uma vez que o senhor de terras era um nobre proprietário e mantinha uma relação entre a posse de terras e o status de classe dominante, do ponto de vista econômico, essa ordem já era considerada obsoleta.

O camponês típico tinha perdido muito da sua condição de servo no final da Idade média, embora ainda frequentemente guardasse muitas marcas amargas da dependência legal. A propriedade típica já de há muito deixara de ser uma unidade de iniciativa econômica e tinha-se tornado um sistema de cobrança de aluguéis e de outros rendimentos monetários. O camponês mais ou menos livre, grande, médio ou pequeno, era o lavrador típico. Se de alguma forma arrendatário, pagava aluguel ao senhor das terras (ou, em algumas áreas, uma quota da safra). (...) Mas, se os vínculos políticos fossem retirados, uma enorme parte da Europa surgiria como uma área de agricultura camponesa. (HOBSBAWM, 2002, p. 36)

A sociedade naquele momento ainda era essencialmente rural. A cidade provinciana vivia basicamente à custa da economia do campo.

Na migração campo-cidade, na busca de trabalho por quem não conseguia arranjar ocupação no campo, a chance para as mulheres era o trabalho doméstico. Segundo Hufton (1991, p.31), a função de criada constituía "o maior grupo trabalhador na sociedade urbana, chegando cerca de doze por cento da população total de qualquer vila ou cidade européia nos séculos XVII e XVIII.", representando também uma oportunidade de trabalho para os homens em residências de aristocratas como cozinheiros, lacaios, mordomos e criados de quarto.

$\mathrm{Na}$ organização da economia familiar - unidade primária sobre a qual se baseava toda a sociedade -, o marido era responsável pelo sustento e abrigo da mulher, pagava os impostos e representava o agregado na comunidade. Numa família camponesa, a mulher desenvolvia várias atividades no apoio da economia familiar, desde o trato com o gado, o cuidado com a horta, o preparo dos alimentos, que envolvia, entre outras coisas, o feitio de pães, queijos e os serviços da casa, ocupando várias tarefas ao longo do ano, ao contrário das tarefas dos maridos, que eram visivelmente demarcadas, começavam e acabavam em horário determinado, o que demonstra como o trabalho das mulheres é refratário à mensuração do tempo.

No final do século XVIII, em algumas regiões da França, aconteceram mudanças nos padrões de trabalho das mulheres no campo, em função do crescimento demográfico e da 
diminuição do número de unidades de subsistência, levando muitas mulheres casadas a se tornarem força de trabalho ocasional nas grandes propriedades e também a formarem um exército de reserva nas tentativas de ingresso nas fábricas. Em algumas regiões era possível encontrar mulheres trabalhando como prestadoras de serviços de apoio em indústrias domésticas e na agricultura em troca de um salário. (HUFTON, 1991). Muitas vezes, como explica Hufton, a indústria regional oferecia oportunidades de trabalho no domicilio para as mulheres, desenhando uma delimitação entre o espaço laboral e as preocupações dos dois sexos a exemplo das comunidades de rendeiras - em que as mulheres permaneciam sentadas de doze a dezesseis horas por dia, enquanto os homens cultivavam as suas pequenas propriedades ou cuidavam dos rebanhos; e das manufaturas de algodão -, que absorviam o trabalho industrial do casal como única fonte de rendimento da família.

No século XIX, o conjunto das transformações econômicas, tecnológicas e sociais ocorridas na Europa, especialmente na Inglaterra, marca o início do desenvolvimento da Revolução industrial e a ascensão do modo de produção capitalista. Ocorreu, sobretudo, a passagem de um sistema essencialmente agrário e artesanal para outro de cunho industrial, dominado por fábricas e maquinaria, baseado na produção de mercadorias, nas relações sociais estabelecidas em dinheiro, na propriedade privada dos meios de produção e na acumulação de capital. Todas essas transformações econômicas, sociais e políticas foram aos poucos se expandindo para o restante da Europa e outros continentes.

As atividades agrícolas na Inglaterra desde o século XVI já estavam amplamente dirigidas para o mercado com o cercamento dos campos destinados à produção de ovelhas para alimentar a indústria têxtil. A agricultura funcionava segundo os fundamentos de um mercado industrializado: garantia do "aumento da produção e a produtividade de modo a alimentar uma população não agrícola" (HOBSBAWM, 2002, p. 54). Os camponeses expulsos de suas terras migravam em massa para as áreas urbanas, formando um exército de reserva para as indústrias, sujeitando-se aos baixos salários e às condições de vida subumanas. O significado de "indústria" e "fábrica" no sentido moderno na Inglaterra era quase exclusivamente referente às unidades têxteis, entretanto a inovação industrial também estava presente em outras mercadorias de consumo, como em outros produtos têxteis, alimentos e bebidas, incentivada pelo crescimento das cidades, embora empregasse poucos trabalhadores em comparação com a indústria algodoeira, e tivesse menor poder de transformação.

As atividades da indústria têxtil se desenvolveram em unidades domésticas, por antigos artesãos independentes, antigos camponeses com tempo de sobra nas estações estéreis do ano, que trabalhavam em suas próprias casas, com a contribuição de mulheres e crianças, para subsistência da família e criação da riqueza social. As mercadorias produzidas eram entregues aos mercadores, que, futuramente, se tornariam os patrões. $\mathrm{O}$ desenvolvimento do setor têxtil foi se acelerando cada vez mais, principalmente com o surgimento da indústria do algodão. Os lucros da atividade beneficiavam-se das vantagens advindas do aumento da produtividade pelo uso da mecanização e da mão de obra, que recebia miseráveis salários e formada por uma maioria de mulheres consideradas mais dóceis e crianças.

O crescimento das indústrias passou a exigir um disciplinamento dos operários para se adequarem ao ritmo regular do trabalho diário sem interrupção, um ritmo diferente do que eles estavam acostumados na rotina do trabalho agrícola ou do artesão independente. Homens e mulheres despossuídos dos meios de produção foram "forçados", em troca de um salário, a assumir novas formas de ocupação. O capital cada vez mais se concentrava nas mãos de uma minoria burguesa, intensificando a miséria e a pobreza. Essa nova realidade causou o descontentamento de parte dos operários que se insurgiu contra as 
máquinas, eclodindo em movimentos espontâneos de trabalhadores da indústria e da população pobre. (HOBSBAWM, 2002).

$\mathrm{Na}$ Inglaterra, na Alemanha e na França, a grande indústria comandada por um gerente, muitos deles oriundos de uma base familiar, passou a conduzir o destino de homens e mulheres e tendeu a desenvolver as concentrações de capital que controlavam cidades ou regiões inteiras, mobilizando um grande exército de trabalho. As pequenas vilas iam se transformando em pequenas cidades e depois em grandes cidades, quando já apresentavam um centro comercial com transações que envolviam os bancos, dispunham de transporte e uma multiplicidade de serviços que atraíam pessoas próximas do campo, mesmo assim muitos trabalhadores ainda permaneciam meio agricultores. Mas, já se evidenciava a separação entre o trabalho industrial e comercial e o trabalho agrícola e, junto a isso, a separação da cidade e do campo, acentuando a divisão do trabalho e a divisão sexual do trabalho. As mulheres das classes populares trabalhavam nos campos e nas manufaturas, nas minas e nas lojas, nos mercados e nas oficinas, teciam e fiavam, fermentavam a cerveja e realizavam outras tarefas domésticas. (SAFIOTTI, 1979).

É importante ressaltar que essas transformações criaram um novo modo de vida capitalista, originando novas formas de produção numa sociedade urbanizada, dominada pelo trabalho produtivo e pelo comércio nas cidades, absorvendo os trabalhadores manuais. $\mathrm{Na}$ medida em que as pessoas se tornavam urbanizadas, o conteúdo do trabalho se modificava, as antigas tradições práticas que haviam sido trazidas do campo ou da cidade pré-industrial tornavam-se irrelevantes ou impraticáveis. A instrução dos trabalhadores era fundamental para atuação da gerência nos países em vias de industrialização. Até os artesões com os conhecimentos básicos de produção artesanal precisavam aprender a habilidade do trabalhador especializado de fábrica.

O desenvolvimento da industrialização, no século XIX, aumenta a divisão sexual entre o trabalho doméstico (não-remunerado), realizado privadamente, e o trabalho externo (remunerado), ao mesmo tempo em que exclui os trabalhadores do controle sobre os meios de produção, exemplificado na realidade comum de vários homens operários que trabalhavam para um empregador fora de casa, demonstrando a separação do lar do trabalho.

$\mathrm{Na}$ economia pré-industrial, como nos ensina Hobsbawm (2000) o trabalho doméstico e a produção eram normalmente uma "unidade singular ou combinada. Eram espaços de produção-reprodução, hierarquizados entre os sexos: as mulheres trabalhadoras, ajudantes dos homens, ocupavam-se diretamente da produção de bens, serviços e da alimentação da família. Embora isto significasse que elas, em grande parte, trabalhassem excessivamente - já que faziam a maior parte do trabalho doméstico e participavam também do resto das atividades, neste sentido, eram diminuídas as diferenças entre trabalhos de homens e trabalhos de mulheres. O movimento de deslocamento do trabalho produtivo do espaço familiar para o espaço da fábrica modifica o domínio das relações entre homens e mulheres, reafirmando o espaço privado, doméstico, como natural às mulheres, determinado pelas necessidades da reprodução e realização das capacidades femininas.

Essas mudanças ocasionaram transformações na divisão sexual do trabalho tanto do ponto de vista produtivo como político. Geralmente, era o homem que deixava a casa diariamente para buscar o sustento da família e não a mulher. Normalmente, ela "trabalhava fora (quando elas, por algum modo, assim o faziam) somente antes do casamento e, depois de casadas, somente caso enviuvassem ou se separassem, ou quando o marido não ganhasse o suficiente para manter a esposa e a família” (idem, p.134). 
O movimento operário (movimentos revolucionários e socialistas do século XIX e primórdios do século XX) respaldava a imagem do casamento e da família como a carreira principal da mulher; brigava pela profissão e o salário do homem, tanto foi assim, que a tendência era lutar pelo cálculo do salário mínimo "desejável em termos de ganhos de um único arrimo de família (isto é, na prática, o homem) e a considerar a esposa trabalhadora assalariada como sintoma de uma situação econômica indesejável." (idem). Os sindicalistas, a exemplo da Grã-Bretanha, do sexo masculino repudiavam qualquer igualdade de trabalho entre homens e mulheres, pela simples razão do fato dos salários das mulheres serem muito baixos, representando uma ameaça aos seus vencimentoss e condições de trabalho. O modelo disso é a manifestação freqüente de desagrado entre os artífices quando ocorria "mistura promíscua de homens e mulheres no convívio diário, quer seja na oficina, quer seja no clube social" (1897 WEBS apud HOBSBAWM, 2000, p. 137).

Como podemos observar a demarcação entre trabalho de homens e trabalho de mulheres pode ser compreendida no curso do desenvolvimento da sociedade industrial. Explicações mais evidentes a respeito da ideologia naturalista que legitima princípios de separação entre os sexos podem ser encontradas no conceito de trabalho. O sentido histórico que essa categoria ocupa no desenvolvimento da sociedade capitalista nos permite tomá-la como fio condutor para estabelecer algumas análises.

A construção de uma nova ideologia do trabalho apropriada pelo modo de produção capitalista foi imperativa para desfigurá-lo da marca da escravidão e ligá-lo à idéia de progresso, à produção e reprodução de novos valores, passando a ser imposto por diversas instâncias e de modo diferenciado conforme cada grupo social.

A noção de trabalho, olhando para o Brasil, herdou do mundo colonial o estigma que envolvia o trabalho manual desenvolvido pelos escravos, como algo degradante que pressupunha para quem o desenvolvesse, a perda da dignidade social e da liberdade. A mudança de regime de trabalho escravo para trabalho de "homens livres" ou "semilivres" nasce assemelhando-se à ordem social do cativeiro e senhorial brasileira, articulado ao mandonismo, ao "paternalismo e ao conformismo, imposto pela sociedade existente, como se o trabalho livre fosse um desdobramento e uma prolongação do trabalho escravo". (FERNANDES, 1973, p. 193). O trabalhador livre encontra-se expropriado de seus meios de produção e de subsistência, coagido a vender a sua força de trabalho para um senhor que se tornara patrão na lavoura ou nos centros urbanos. A adaptação às novas relações de produção passava pela constituição e difusão de uma nova ideologia do trabalho que atendesse às necessidades do capital: a produção de mais-valia. A nova ordem põe em marcha a redefinição do trabalhador segundo a ordem capitalista (e a sua resistência a ela) no intuito de controlar as suas ações não só nos espaços de trabalho, mas, também, em suas relações pessoais e familiares, em casa ou na rua.

A questão central era a conformação de um mercado livre capitalista e a elaboração de novas formas de racionalização do trabalho. Os trabalhadores urbanos que compunham a classe operária foram formados segundo métodos de controle de trabalho para ser economicamente produtivos. O eixo principal desses métodos consistia em educar o trabalhador para ser disciplinado, dócil, integrando-se, com sua família, aos valores burgueses, por meio de mecanismos de controle e vigilância que atuavam no interior da fábrica, mas também fora dela, haja vista a redefinição da organização da família e a reafirmação do modelo de mulher voltada para intimidade do lar, apesar da presença crescente delas no mercado de trabalho.

A intenção era sedimentar a noção de que o trabalho era uma virtude, espaço de liberdade, um bem regulado pelo pacto social, uma vez que orientava os padrões de 
conduta social e familiar no sentido de mostrar que o "homem de bem", ao contrário do "desordeiro", era alguém que trabalhava, seguia as regras estabelecidas e cumpria com as suas funções de chefe de família.

O Estado burguês universaliza a condição de homens e mulheres em cidadãos, em indivíduos "livres e iguais" desde o nascimento, contudo, como bem nos lembra Noronha (2004), nesse contexto em que as relações sociais básicas sempre foram circunscritas entre o senhor e o escravo, era difícil promover, o trabalhador, à condição de homem livre no sentido de gozar de autonomia e sentimentos de pleno direito e, além disso, deve-se observar desde o princípio que os "indivíduos livres" eram do sexo masculino e donos de novas classes médias, ou a burguesia.

Os novos discursos sobre o trabalho (e o seu antônimo) em uma sociedade formada por trabalhadores e trabalhadoras, homens e mulheres de diferentes classes sociais, brancos, negros, foram construídos de diversas maneiras, designando as funções de acordo com o status quo de cada grupo:

Atividades intelectuais e de gerência para os da elite, serviços manuais para as classes populares, trabalhos próprios para as mulheres e próprios para os homens, corpos bronzeados e musculosos para os trabalhadores, peles brancas e lassas para a elite, "vocações" masculinas e femininas, um ócio admitido e adequado para as mulheres da elite, e um ócio negativo, a ser combatido nas classes populares, enfim disposições para diferentes atividades segundo os diferentes grupos sociais. (LOURO, 1992, p. 64-65).

As explicações da autora nos mostram que em cada tempo e em cada espaço, as ocupações exercidas por homens e mulheres de diferentes classes sociais têm lugares e papéis definidos no trabalho, na família e na sociedade. É importante lembrar que as mulheres pobres sempre trabalharam regularmente fora de casa, como domésticas, operárias, ou realizavam trabalhos produtivos informais, remunerados ou não na unidade familiar, como lavadeiras, costureiras, cozinheiras.

No que diz respeito aos trabalhadores e trabalhadoras, considerando a divisão sexual do trabalho, vale destacar, em que pese à exploração sofrida pelos operários, a tradição de inferioridade, da qual tem sido vítima historicamente a mulher, contribuiu para que o capitalismo em formação extraísse o máximo de mais-valia absoluta da intensificação do trabalho, do prolongamento da jornada de trabalho e de salários mais baixos que os masculinos, por meio da "marginalização das funções produtivas e emprego da sua força de trabalho". (SAFIOTTI, 1979, p. 40).

Um dos pontos que podemos aprofundar a discussão em torno da contínua inferiorização e intensificação da força de trabalho feminina é o seu emprego na indústria, a partir do desenvolvimento da maquinaria, no qual desde os seus modelos mais primitivos em substituição à mão criou postos de trabalho para as mulheres, principalmente nas indústrias texteis. A alteração da base técnica da produção na indústria simplificou o trabalho operário, tornando-o mais independente da habilidade do trabalhador. Marx e Engels (1998, p.15) destacaram no Manifesto do Partido Comunista que "quanto menos o trabalho exige habilidade e força, isto é, quanto mais a indústria moderna progride, tanto mais o trabalho dos homens é suplantado pelo das mulheres e crianças." A evolução técnica anula a diferença muscular, um dos atributos valorizados na força de trabalho masculina que separa o homem da mulher. A maquinaria abre as portas para elas desenvolverem as mesmas funções, no entanto, a força de trabalho feminina era reconhecida e utilizada, por empregadores, como fonte de mão de obra barata, pouco 
produtiva e adequada para determinados tipos de trabalho, razões que explicam a entrada das mulheres na manufatura.

Portanto, se a máquina iguala a capacidade da mulher à do homem em termos de exigência de força física, dirime os pressupostos que estrutura a segregação sexual no mercado de trabalho em termos de fragilidade do corpo feminino, entretanto, na prática as mulheres na indústria sempre ocuparam as posições mais desvalorizadas. Raramente se abriram para elas horizontes profissionais mais amplos, o exemplo disso é a preocupação com a educação das mulheres dirigida para exercer a carreira doméstica.

Quando transportamos essas análises para os dias atuais, atentando para os grandes avanços tecnológicos, principalmente no que diz respeito à relação diferenciada entre os sexos com a técnica, podemos observar as conseqüências da mecanização e automação. No âmbito dessa discussão, Hirata (2002, p. 207-219) questiona de que modo a tecnologia interfere na organização do trabalho, nos postos, na qualificação do trabalho quando se tratam de homens ou de mulheres. Para responder a esta questão a autora relata conclusões de vários estudos em ramos industriais. Nas unidades reconhecidas como "redutos masculinos", a exemplo dos ramos de siderurgia, petroquímica, o desenvolvimento tecnológico (introdução da microeletrônica) reafirmou a presença masculina no processo de produção e o critério de trabalho que de modo nenhum exige força física, não explica a divisão sexual dessas indústrias, mas sim a "apropriação masculina da tecnologia"; nesse espaço as mulheres são empregadas nos escritórios e laboratórios. Outras indústrias, a exemplo da produção gráfica de livros e automobilísticas, criaram redutos femininos com postos de trabalhos menos qualificados. Nas indústrias têxteis, espaço tradicional feminino, a presença das novas tecnologias muda a divisão sexual do trabalho ao expulsar a mão de obra feminina presente anteriormente em certo número de postos qualificados, tornando efetiva a entrada de homens.

Em pesquisa realizada em indústrias de laticínios, Alves (2010) observou que há unidades de lácteos na Mesorregião Centro-Sul Baiano ${ }^{4}$ que as mulheres são excluídas do espaço da fábrica, por adotarem o discurso ideológico que legitima a "naturalidade" da distinção entre trabalho "leve", trabalho de mulher e "pesado", trabalho de homem, marginalizando a força de trabalho feminina das funções produtivas, independente se a indústria possui ou não uma base tecnológica desenvolvida. Outras unidades ${ }^{5}$ empregam a força de trabalho feminina como um elemento coadjuvante, secundário, em funções que reproduz o serviço doméstico, restando para elas poucas oportunidades de desenvolver um "potencial criador" e formativo comparado com o trabalho dos homens. É importante ainda considerar que se nas indústrias o trabalho desenvolvido pela mulher é considerado "leve" por gerentes e até os mesmos os seus colegas, ninguém se lembra de ressaltar que é exigido também para elas (tanto quanto a eles) o cumprimento de uma longa jornada e imposições por rapidez e ritmo.

Enfim, o que desejamos assinalar aqui é que a divisão de atividades nos espaços de trabalhos é sempre reconstruída, como também a concepção de trabalho, portanto, as funções que são designadas para as mulheres são representações e remonta a um significado histórico-cultural, decorrente da relação social entre os sexos como apontam Hirata e Kergoat (2007), que tem como característica o destino prioritário dos homens à esfera produtiva e o das mulheres à função básica e primordial de cuidar da vida privada e da esfera doméstica (esfera reprodutiva), espaço desvalorizado socialmente e, simultaneamente, a apropriação pelos homens das funções com maior valor social adicionado, condicionando as práticas dicotomizadoras que atribuem lugares e funções diferentes e hierarquizados entre os sexos. 


\section{CONSIDERAÇÕES FINAIS}

As análises elaboradas por Abramo (2007) ajudam-nos a compreender a discriminação feminina no mercado de trabalho do ponto de vista do "imaginário social" com base em dimensões segundo o senso comum e a ideologia empresarial. Na primeira dimensão, é formulada a "idéia de mulher como força de trabalho secundária" (p.28), origina-se do modo como a família nuclear foi organizada e construída socialmente, em que o homem é considerado como o principal provedor do lar enquanto a mulher é responsável pelo cuidado da casa e da família. Na segunda, os argumentos são que as mulheres não têm o trabalho como uma obrigação e por essa razão estariam dispostas a ganhar menos para "terem mais tempo para a família" (p. 31). Ou seja, vários argumentos que sustentam a desvalorização do trabalho da mulher no mercado de trabalho e valorizam socialmente o homem

No tocante ao grau de escolaridade é crescente a presença das mulheres nos diversos níveis de ensino e em atividades profissionais valorizadas, entretanto, observamos que em termos de igualdade entre os sexos, a situação precária das mulheres das classes populares não foi suplantada.

Embora seja por demais conhecida a ideia de que não há um único modelo de família, a exemplo do crescimento de famílias chefiadas por mulheres $(30,6 \%$ em 2005 , segundo o IBGE), tendo em vista a efetiva participação delas na produção econômica (IBGE, 2006) e essas constatações abalarem o conceito de masculino provedor, mesmo assim ainda é forte entre as instituições a imagem secundária da mulher no mundo do trabalho: a pessoa mulher só é considerada necessária por falta de alternativas, dentre as quais o desemprego do homem, morte ou doença deste.

A generalização do retrato da permanência e reprodução histórica das desigualdades entre os sexos no mundo do trabalho mostra que a realidade é construída em torno de argumentos que originam lugares e funções diferentes, hierarquização de qualificação e da carreira entre homens e mulheres, designando-as como força de trabalho acessória. Na divisão sexual do trabalho que acontece dentro da fábrica, de modo geral as funções de concepção e chefia são ocupadas por homens, enquanto aquelas atividades que não exigem alta qualificação, são mais elementares destinam-se às mulheres trabalhadoras. A conservação e reprodução dessas desigualdades são marcadas por fatores originados da divisão sexual do trabalho e das relações entre os sexos, que designam prioritariamente à mulher a função de cuidar da vida privada e doméstica, acompanhada de sua exclusão do campo sociopolítico e, ao mesmo tempo, atribui ao universo doméstico um valor social inferior ao mundo "público".

\section{REFERÊNCIAS}

ABRAMO, Laís. Inserção das mulheres no mercado de trabalho na América Latina: uma força de trabalho secundária?. In: HIRATA, Helena; SEGNINI, Liliana (Orgs.).

Organização, trabalho e gênero. São Paulo: Editora Senac, 2007.

ALVES, A. E. S. Formação e divisão sexual do trabalho na fabricação de queijos: da unidade de produção tradicional rural à unidade de produção moderna. 2010. $110 \mathrm{f}$. Relatório de estágio de pós-doutoramento apresentado ao programa de pós-graduação em educação da Unicamp, Campinas, SP. 2010. 
BEAUVOIR, Simone de. O segundo sexo, vol 1. Tradução de Sérgio Milliet. São Paulo: Circulo dos Livros, 1949.

CASTEL, R. As metamorfoses da Questão Social: uma crônica do salário. Rio de Janeiro: Vozes, 1998. (Col. Zero à Esquerda).

DUBY, G. Os Camponeses. In: Guerreiros e Camponeses: os primórdios do crescimento econômico europeu séc. VII - XII. 2.ed. Lisboa, PT: Estampa, 1993, p. 197 226.

ENGELS, Friedrich. A origem da família, da propriedade privada e do Estado. 4 ed. Rio de Janeiro: Global, 2002.

FALCON, Francisco J.C. O capitalismo unifica o mundo. In: REIS FILHO, Daniel Aarão; FERREIRA, J.; ZENHA, C. O século XX. O tempo das certezas: da formação do capitalismo à Primeira grande guerra. Rio de Janeiro: Civilização Brasileira, 2000, v 1. p. 12-76.

FERNANDES, Florestan. Capitalismo dependente e classes sociais na America Latina. Rio de Janeiro: Zahar Editores, 1973.

HIRATA, Helena. Nova divisão sexual do trabalho?Um olhar voltado para a empresa e a sociedade. São Paulo: Boitempo Editorial, 2002.

; KERGOAT, Danièle. Novas configurações da divisão sexual do trabalho.

Cadernos de Pesquisa. v.37, n.132, p.595-609, set/dez.2007.

HOBSBAWM, Eric J. A era das revoluções 1789-1848. 16ª Ed. Tradução de $M^{\mathrm{a}}$ Tereza L. Teixeira e Marcos Penchel. São Paulo: Paz e Terra, 2002.

. Mundos do Trabalho: novos estudos sobre História operária. 3 ed. Tradução W. Barcelos e S. Bedran. RJ: Paz e Terra, 2000.

HUFTON, Olwen. Mulheres, trabalho e família. In: DUBY, Georges; PERROT, Michelle. História das Mulheres no Ocidente: Do renascimento à Idade Moderna. Tradução de Alda Maria Durães et al. Porto, PT: Edições Afrontamento, 1991.

IBGE. Anuário Estatístico. Dados Gerais, v.65, 2005. p 4-13.

IBGE. Síntese de Indicadores Sociais 2006. Comunicação Social 20 de dezembro de 2006.

Disponível em:

http://www.ibge.gov.br/home/presidencia/noticias/noticia_impressao.php?id_noticia=774. Acesso em: 16/08/2010.

LE GOFF, J. Tempo e Trabalho. Para um novo conceito de idade média: tempo, trabalho e cultura no ocidente. Tradução de Maria Helena da C. Dias. Lisboa, PT: Estampa, 1993.

LOURO, G. L. Uma leitura da história da educação sob a perspectiva do gênero. Teoria \& Educação. Porto Alegre, RS, v.6, p.53-67, 1997.

OPITZ, C. O quotidiano da mulher no final da Idade Média (1250-1500). In: KLAPISCHZUBER, C. História das Mulheres no Ocidente: A idade média. Tradução de Ana L.

Ramalho et al. Porto, PT: Afrontamento, 1990, p.353-435.

MARX, K.; ENGELS, F. A ideologia alemã. Tradução de R. Enderle, N. Schneider e L.C. Martorano. São Paulo: Boitempo, 2007. 
; ENGELS, F. Manifesto do Partido Comunista. In: REIS FILHO, Daniel Aarão (Org.). O manifesto Comunista 150 anos depois: Karl Marx, Friedrich Engels. São Paulo: Fundação Perseu Abramo, 1998, p. 7-41.

NORONHA, Olinda Maria. Ideologia, trabalho e educação. Campinas, SP: Editora Alínea, 2004.

PANTEL, P. S. Introdução: Um fio de Ariadne. In: DUBY, G; PERROT, M. História das mulheres no ocidente: A antiguidade. Tradução de Maria Helena da Cruz Coelho et al. Porto, PT: Afrontamento, 1990, p. 19-27.

SAFFIOTI, H. A mulher na sociedade de classes: mito e realidade. Petrópolis, RJ: Vozes, 1979.

SENNETT, R. O artífice. Tradução de Clóvis Marques. Rio de Janeiro: Record, 2009.

\footnotetext{
${ }^{1}$ As análises aqui presentes integram relatório de pesquisa realizado em estágio de pós-doutoramento, no Programa de Pós-graduação da Faculdade de Educação da Unicamp, em 2010, tendo como interlocutor o prof Dermeval Saviani.

${ }^{2}$ Professora da Universidade Estadual do Sudoeste da Bahia - UESB. Membro do Museu Pedagógico da UESB. Email: ana_alves183@hotmail.com

${ }^{3}$ Vale ressaltar que esse processo não seguiu um curso linear. Ainda hoje, coexistem diferentes sistemas familiares na sociedade mundial. Por outro lado, elementos que compõem um mesmo sistema familiar estão sujeitos, cada um, a sofrer diferentes ritmos evolutivos.

${ }^{4}$ A exemplo de uma indústria na região de Itambé, BA, e outra na cidade de Itapetinga, BA.

${ }^{5} \mathrm{Na}$ mesma região.
}

Recebido em 23/01/2011

Aprovado em 30/03/2011 